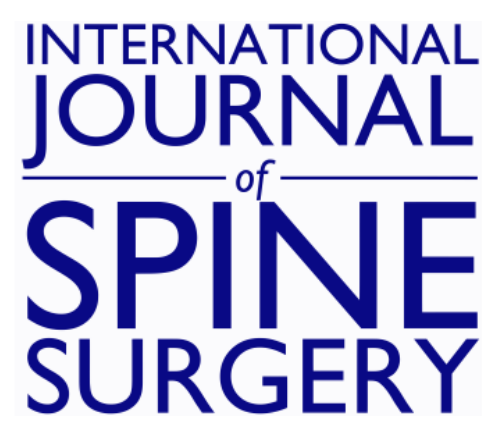

\title{
An Evidence-Based Algorithm for Determining Venous Thromboembolism Prophylaxis After Degenerative Spinal Surgery
}

JOSHUA A. SHAPIRO, MATTHEW R. STILLWAGON, ALEXANDER G. PADOVANO, STEPHAN MOLL and MOE R. LIM

Int J Spine Surg 2020, 14 (4) 599-606

doi: https://doi.org/10.14444/7080

http://ijssurgery.com/content/14/4/599

This information is current as of April 26, 2023.

Email Alerts Receive free email-alerts when new articles cite this article. Sign up at: http://ijssurgery.com/alerts

The International Journal of Spine Surgery 2397 Waterbury Circle, Suite 1, 


\title{
An Evidence-Based Algorithm for Determining Venous Thromboembolism Prophylaxis After Degenerative Spinal Surgery
}

\author{
JOSHUA A. SHAPIRO, MD, ${ }^{1}$ MATTHEW R. STILLWAGON, MD,${ }^{1}$ ALEXANDER G. PADOVANO, MD, ${ }^{1}$ \\ STEPHAN MOLL, MD, ${ }^{2}$ MOE R. LIM, MD ${ }^{1}$ \\ ${ }^{I}$ University of North Carolina, Department of Orthopaedics, Chapel Hill, North Carolina, ${ }^{2}$ University of North Carolina, Department of Medicine, Division of \\ Hematology/Oncology, Chapel Hill, North Carolina
}

\begin{abstract}
Background: Although venous thromboembolism (VTE) is a potentially serious and life-threatening complication, there is no widely accepted protocol to guide VTE prophylaxis in adult degenerative spinal surgery, and pharmacologic overtreatment may result in hemorrhagic complications. Previously, we published the VTE Prophylaxis Risk/Benefit Score, an evidence-based algorithm that balances the risk and consequences of thrombotic versus hemorrhagic complications by taking consideration of patient-related risks, procedure-related risks, and the risk of neurological compromise to guide VTE prophylaxis. To objective of this study was to validate the VTE Prophylaxis Risk/Benefit Score.

Methods: From January 1, 2016, to December 31, 2017, VTE Prophylaxis Risk/Benefit Scores and corresponding prophylaxes were prospectively assigned. When indicated, chemoprophylaxis was dosed 24 to 36 hours postoperatively to allow for adequate surgical hemostasis. Patients were retrospectively evaluated for immediate and short-term complications. The Fisher exact test compared incidence of complications by VTE prophylaxis. Multinomial logistic regression modeled the probability of complication by prophylaxis type, demographics, and comorbidities. Significance was set at $P<.05$.

Results: Of the 266 patients who met inclusion criteria, $79.3 \%$ were given mechanical prophylaxis alone and $20.7 \%$ were given combined mechanical and chemical prophylaxis. Complications including VTE $(0.38 \%)$, delayed wound healing or infection $(2.26 \%)$, and hematoma $(0.75 \%)$ were observed at rates similar to or lower than previously published studies with increased utilization of chemoprophylaxis. Use of chemoprophylaxis and continuation of perioperative aspirin were significantly associated with the development of a hemorrhagic complication. No patient developed persistent neurologic deficit from hematoma or pulmonary embolism.

Conclusions: The VTE Prophylaxis Risk/Benefit Score comprehensively considers the risk of thrombotic, wound, and bleeding complications and is an effective tool for determining appropriate thromboprophylaxis in adult degenerative spinal surgery.
\end{abstract}

Level of Evidence: 3.

\section{Complications}

Keywords: venous thromboembolism, chemical thromboprophylaxis, mechanical thromboprophylaxis, algorithm, riskbenefit, hemorrhagic complication rate, wound complication rate, deep infection rate

\section{INTRODUCTION}

Venous thromboembolism (VTE) is an infrequent, but potentially serious complication in adult degenerative spine surgery. The risk of symptomatic thrombosis after operations for degenerative spine diseases ranges from $1.0 \%$ to $1.9 \%^{1}$; however, some studies report up to $31 \%$ incidence of VTE with routine postoperative surveillance, and the North American Spine Society (NASS) concluded that the incidence of postoperative thrombosis is poorly understood. ${ }^{2}$ Mechanical prophylaxis in the form of graduated compression stockings and intermittent pneumatic compression devices may reduce the incidence of VTE by $60 \%$ to $66 \%^{3-5}$ and is recommended in the $\mathrm{NASS}^{2}$ and American College of Chest Physicians (ACCP) ${ }^{6}$ guidelines for all adult degenerative spinal surgeries. Adjunctive therapy with chemoprophylaxis including antiplatelet agents, vitamin $\mathrm{K}$ antagonists, unfractionated heparin, low-molecular-weight heparins, factor $\mathrm{Xa}$ inhibitors, and thrombin inhibitors may reduce the 
Table 1. The VTE Prophylaxis Risk/Benefit Score. ${ }^{14}$ The summation of patient-related VTE risk, surgical procedure-related VTE risk, and neurologic risk of bleeding complications equals the VTE Prophylaxis Risk/Benefit Score.

\begin{tabular}{|c|c|c|}
\hline \multicolumn{3}{|c|}{ Patient-Related VTE Risk } \\
\hline $\begin{array}{l}\text { Low Risk }(0) \\
\text { No comorbidities } \\
\text { Diabetes mellitus } \\
\text { Hypertension } \\
\text { Hyperlipidemia }\end{array}$ & $\begin{array}{l}\text { Moderate Risk ( }+1 \text { for } 1 ;+2 \text { for multiple) } \\
\text { Age }>60 \\
\text { Body mass index } \geq 30 \mathrm{~kg} / \mathrm{m}^{2} \\
\text { Smoking } \\
\text { Estrogen-containing } \\
\text { contraceptives (pill, patch, ring), injectable } \\
\text { progestin contraceptives, hormone } \\
\text { replacement therapy, pregnancy } \\
\text { Congestive heart failure } \\
\text { Limited pulmonary reserve/pulmonary } \\
\quad \text { circulation disorder } \\
\text { First-degree relative with VTE } \\
\text { Poor mobilization after surgery } \\
\text { ASA Class } \geq 3\end{array}$ & $\begin{array}{l}\text { High Risk }(+3) \\
\text { History of VTE } \\
\text { Spinal cord injury } \\
\text { Multiple trauma } \\
\text { Active malignancy }\end{array}$ \\
\hline \multicolumn{3}{|c|}{ Surgical Procedure-Related VTE Risk } \\
\hline $\begin{array}{l}\text { Low Risk }(0) \\
\text { Posterior lumbar decompression } \\
\text { Anterior cervical fusion/disk replacement } \\
\text { Posterior cervical decompression }\end{array}$ & $\begin{array}{l}\text { Moderate Risk }(+1) \\
\text { Posterior lumbar fusion } \\
\text { Posterior cervical fusion }( \pm \text { anterior fusion) } \\
\text { Anterior lumbar interbody fusion/disk } \\
\text { replacement. } \\
\text { Oblique lumbar or extreme lateral } \\
\text { interbody fusion ( } \pm \text { minimally invasive } \\
\text { posterior instrumentation) } \\
\quad \text { Neurological Risk of Bleeding Complications }\end{array}$ & $\begin{array}{l}\text { High Risk }(+3) \\
\text { Extensive }(4 \text { or more levels) posterior } \\
\text { thoracolumbar fusion } \\
\text { Combined open anterior/ posterior major } \\
\text { reconstructive thoracolumbar fusion }\end{array}$ \\
\hline $\begin{array}{l}\text { Low }(+1) \\
\text { No decompression (no neurological risk) } \\
\text { Nerve root decompression (negligible } \\
\text { neurological risk) }\end{array}$ & $\begin{array}{l}\text { Moderate }(0) \\
\text { Lumbar central canal/cauda equina } \\
\text { decompression (moderate neurological risk) } \\
\quad \text { VTE Prophylaxis Risk/Benefit Score }\end{array}$ & $\begin{array}{l}\text { High }(-1) \\
\text { Cervical/thoracic spinal cord decompression } \\
\text { (high neurological risk) } \\
\text { Excessive bleeding intraoperatively }\end{array}$ \\
\hline $\begin{array}{l}\leq 1 \\
\text { PSCDs and CS with early mobilization }\end{array}$ & $\begin{array}{l}2 \\
\text { PSCDs and CS with early mobilization. } \\
\text { Possible chemical prophylaxis based } \\
\text { on additional individual factors and } \\
\text { surgeon discretion }\end{array}$ & $\begin{array}{l}\geq 3 \\
\text { PSCDs and CS with early mobilization. } \\
\text { Chemoprophylaxis with enoxaparin } 40 \mathrm{mg} \text { daily } \\
\quad \text { (first dose } 24-36 \text { h postoperatively). } \\
\text { Duration: hospitalization only for mobile and } \\
\text { until 2-week follow up for less mobile } \\
\text { individuals. }\end{array}$ \\
\hline
\end{tabular}

Abbreviations: VTE indicates venous thromboembolism; CS, compression stockings; PSCDs, pneumatic sequential compression devices; ASA, American Society of Anesthesiologists.

incidence of VTE by an additional $30 \%$ to $74 \%{ }^{7-13}$ and is recommended by the $\mathrm{ACCP}^{6}$ and $\mathrm{NASS}^{2}$ when there is sufficient risk for VTE and when adequate hemostasis has been achieved.

It is well understood that surgery creates a prothrombotic state and to prevent VTE safely and effectively, homeostasis in thrombosis and thrombolysis must be achieved. Undertreatment may lead to VTE, while pharmacologic overtreatment may lead to hemorrhagic complications including hematoma and wound dehiscence resulting in infection. In a decompressed and unprotected spinal cord or spinal nerve root, these unintended consequences may lead to devasting neurologic decline. ${ }^{1,2,14-17}$ The incidence of post-chemoprophylaxis epidural hematoma ranges from $0.3 \%$ to $3.5 \%^{1,18-20}$; the majority of patients with this complication require surgical evacuation and up to
$50 \%{ }^{21,22}$ may be left with persistent neurologic deficit.

In 2015, we published the VTE Prophylaxis Risk/ Benefit Score, an evidence-based algorithm to guide VTE prophylaxis decisions after operations on the adult degenerative spine. ${ }^{14}$ This algorithm considered (1) patient-related VTE risks, (2) procedurerelated VTE risks, and (3) the risk of neurological compromise from bleeding complications to more appropriately balance safety and effectiveness when choosing a VTE prophylaxis method. The sum of the 3 risk scores corresponds to a recommendation for thromboprophylaxis - either mechanical alone (score $\leq 1)$ or in conjunction with pharmacologic prophylaxis (score $\geq 3$ ) (Table 1). Should a final score of 2 be calculated, then the surgeon may use his or her clinical judgement to recommend pharmacologic or mechanical prophylaxis, if for 
example, numerous moderate risk factors are present.

Our senior spine surgeon has implemented the VTE Prophylaxis Risk/Benefit Score since its inception in 2015. During this time, similar scoring symptoms for spine surgery have been developed, but none have been universally adopted by surgeons. ${ }^{18,23}$ VTE prophylaxis in adult spinal surgery remains controversial. ${ }^{14,18,20,23}$ In this analysis, we aimed to determine whether the VTE Prophylaxis Risk/Benefit Score can safely and effectively guide thromboprophylaxis following adult degenerative spinal surgery.

\section{MATERIALS AND METHODS}

Approval was obtained from the Institutional Review Board prior to implementation of this study. From January 1, 2016, to December 31, 2017, patients who underwent surgery for degenerative spinal conditions by a single board-certified orthopedic spine surgeon at our academic medical center were assigned a VTE Prophylaxis Risk/Benefit Score $^{14}$ and received corresponding thromboprophylaxis.

Adult patients $(\geq 18$ years old) undergoing elective degenerative spine surgery were included. VTE Prophylaxis Risk/Benefit Scores and thromboprophylaxis were prospectively assigned at the time of surgery. All patients received mechanical prophylaxis with pneumatic sequential compression devices worn while inpatients and graduated compression stockings worn until 2 weeks postoperatively. If indicated, chemical prophylaxis was initiated 24 to 36 hours postoperatively to allow for sufficient hemostasis. ${ }^{2,6}$ The duration of lowmolecular-weight heparin (LMWH) thromboprophylaxis corresponded to postoperative mobility. Patients who demonstrated the ability to ambulate with minimal assistance, as determined by the treating physical therapist, at least twice per day by the second postoperative day were indicated for inpatient-only LMWH, whereas those who were less ambulatory were indicated for extended outpatient LMWH. Individuals who were prescribed long-term aspirin for cardiovascular protection were instructed to hold the medication for 1 week preoperatively and resume the medication on the first postoperative day regardless of VTE Risk/Benefit Score. Holding aspirin postoperatively has been associated with an increased prothrombotic state in patients requiring aspirin for secondary prophylaxis for cardiovascular disease. $^{24}$ Individuals who were prescribed longterm anticoagulation by a primary care physician or hematologist were excluded. All patients were instructed to mobilize with physical therapy and nursing when tolerated and no later than the first postoperative day. Minimum follow-up was set at 3 months to capture surgically provoked VTE events. Within this timeframe, duplex ultrasonography was ordered on patients who presented with signs of VTE such as extremity pain, asymmetric edema, or chest pain to confirm the diagnosis and begin therapeutic anticoagulation.

Patient data in addition to VTE Prophylaxis Risk/Benefit Scores and thromboprophylaxis including age at time of surgery, sex, operative reports, smoking status, body-mass index, American Society of Anesthesiologists scores, medical comorbidities, and postoperative mobilization were collected from the electronic medical record via review of physician, nursing, and therapy notes. Thrombotic, hemorrhagic, infectious, and wound complications were identified similarly. Superficial skin infections without associated drainage, such as suture abscess and incisional cellulitis, were excluded.

\section{Statistical Methods}

The Fisher exact test was used to compare the incidence of complications by VTE prophylaxis method. Logistic regression models were then used to model the probability of complication as a function of patient demographics, comorbidities, use of aspirin, American Society of Anesthesiologists score, surgery type, VTE Risk/Benefit Score, and VTE prophylaxis used in order to isolate significant associations. The rate of observed complication was compared to a range presented by prior studies. The analysis was conducted using SPSS Statistics (IBM, Armonk, New York). Significance was set at $P<.05$.

\section{RESULTS}

Two hundred eighty-eight patients met screening criteria. Three patients were excluded for incomplete data, 4 patients were excluded for less than 3-month follow-up, and 15 patients were excluded for longterm anticoagulation. Of the 266 included, there were 136 cervical $(51.1 \%)$ and 130 thoracolumbar $(48.9 \%)$ cases. The average age (mean \pm SD), was $56.8 \pm 13.7$ years. The average body mass index was 


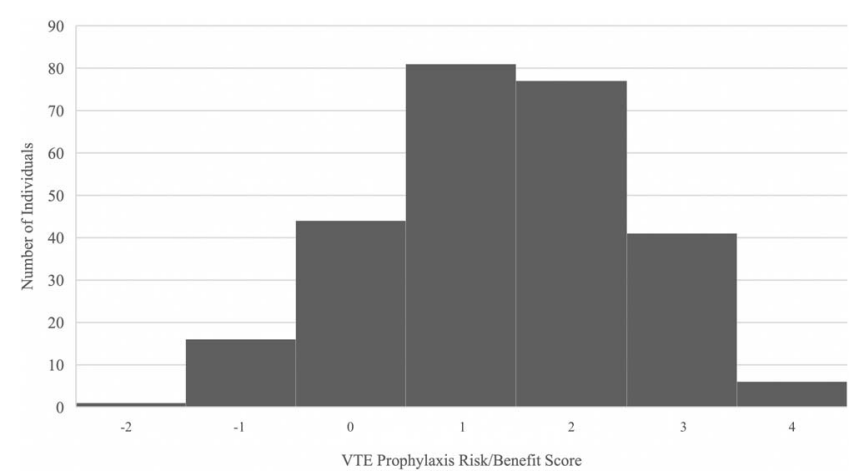

Figure 1. Histogram of VTE Prophylaxis Risk/Benefit Scores. VTE Prophylaxis Risk/Benefit Scores followed a normal Gaussian distribution. VTE indicates venous thromboembolism.

$30.3 \pm 6.3 \mathrm{~kg} / \mathrm{m}^{2}$, which followed a normal Gaussian distribution. There were 39 (14.7\%) active tobacco users and 64 (24.1\%) former tobacco users. VTE Risk/Benefit Scores ranged from -2 to 4 and followed a normal Gaussian distribution (Figure 1). Mechanical prophylaxis alone was given to 211 patients $(79.3 \%)$, while $55(20.7 \%)$ received adjunctive chemoprophylaxis. Of the patients who received chemoprophylaxis, 10 received enoxaparin $40 \mathrm{mg}$ daily while inpatients and 45 received extended enoxaparin $40 \mathrm{mg}$ daily until the 2 -week postoperative appointment (Table 2). At the critical score of 2, where surgeon discretion dictated prophylaxis, 69 $(89.6 \%)$ received mechanical prophylaxis alone and 4 each $(5.2 \%)$ received inpatient enoxaparin and extended enoxaparin - a personal history of VTE (n $=3$ ), active malignancy $(\mathrm{n}=1)$, and more than 4 moderate-risk patient-related VTE risk factors $(\mathrm{n}=$ 4) drove the senior author's decision for chemoprophylaxis.

Complications including deep vein thrombosis $(0.38 \%)$, delayed wound healing or deep infection $(2.26 \%)$, and hematoma $(0.75 \%)$ were observed. The incidence of delayed wound healing or deep infection was highest in the group that received enoxaparin until the 2-week postoperative visit, followed by inpatient enoxaparin, and mechanical prophylaxis only. No difference was observed in the incidence of hematoma or VTE among the VTE prophylaxis methods used (Table 3). Multinomial logistic regression identified that use of enoxaparin for 2 weeks (odds ratio $[\mathrm{OR}]=5.9$, confidence interval $[\mathrm{CI}]: 1.2-27.8, P=.03)$ and perioperative use of aspirin (OR: 6.0, CI: 1.2-31.3, $P=.03$ ) were associated with the development of a hemorrhagic or wound complication. The use of enoxaparin for inpatient duration only demonstrated a marginal association $(\mathrm{OR}=6.7$, $\mathrm{CI}$ : 0.6-75.6, $P=.12)$, but was underpowered. The remainder did not display significant associations $(P>.24)$.

The 2 individuals who developed epidural hematoma returned to the operating room for evacuation, and neither suffered long-term neurologic deficit. The one VTE event occurred 3 months postoperatively in a patient following a posterior lumbar decompression and fusion who was given mechanical prophylaxis only for a corresponding VTE Risk/Benefit Score of 2. The patient was treated with rivaroxaban for 6 months uneventfully.

\section{DISCUSSION}

The VTE Prophylaxis Risk/Benefit Score effectively stratifies the risk of perioperative thrombotic and hemorrhagic consequences to safely and effectively guide a physician in choosing a thromboprophylaxis method. Although only $20.7 \%$ of patients in our study received LMWH as chemoprophylaxis, the incidence of VTE, hematoma, delayed wound healing, and deep infection compared favorably to what has been previously reported in the literature (Table 4). This utilization is in line with recommendations from both the $\mathrm{NASS}^{2}$ and $\mathrm{ACCP}^{6}$ and in

Table 2. Average VTE Prophylaxis Risk/Benefit Score and corresponding VTE prophylaxis by surgery. ${ }^{a}$

\begin{tabular}{|c|c|c|c|c|c|}
\hline Surgery & $\mathbf{N}$ & $\begin{array}{c}\text { Average Risk/ } \\
\text { Benefit Score }\end{array}$ & $\begin{array}{l}\text { Mechanical Only } \\
(n=211), \%(n)\end{array}$ & $\begin{array}{c}\text { Enoxaparin } \\
(\text { Inpatient Only) } \\
(\mathrm{n}=10), \% \text { (n) }\end{array}$ & $\begin{array}{c}\text { Enoxaparin } \\
\text { (Extended) } \\
(\mathrm{n}=\mathbf{4 5}), \%(\mathrm{n})\end{array}$ \\
\hline Anterior cervical fusion/disk replacement & 113 & 0.5 & $96.4(109)$ & $1.8(2)$ & $1.8(2)$ \\
\hline Anterior lumbar interbody fusion/disk replacement & 6 & 2.5 & $50.0(3)$ & $0.0(0)$ & $50.0(3)$ \\
\hline Combined open anterior/posterior thoracolumbar fusion & 1 & 3.0 & $0.0(0)$ & $0.0(0)$ & $100.0(1)$ \\
\hline Extensive posterior thoracolumbar fusion ( $\geq 4$ levels) & 1 & 4.0 & $0.0(0)$ & $0.0(0)$ & $100.0(1)$ \\
\hline Posterior cervical decompression & 2 & 1.0 & $100.0(2)$ & $0.0(0)$ & $0.0(0)$ \\
\hline Posterior cervical fusion & 21 & 1.7 & $90.5(19)$ & $9.5(2)$ & $0.0(0)$ \\
\hline Posterior lumbar decompression & 59 & 1.6 & $89.8(53)$ & $0.0(0)$ & $10.1(6)$ \\
\hline Posterior thoracolumbar or lumbar fusion ( $\leq 3$ levels) & 63 & 2.5 & $39.7(25)$ & $9.5(6)$ & $50.8(32)$ \\
\hline
\end{tabular}

Abbreviation: VTE indicates venous thromboembolism.

${ }^{a}$ All patients received mechanical prophylaxis with pneumatic sequential compression devices and compression stockings. If indicated, chemoprophylaxis was added 24-36 hours postoperatively after adequate hemostasis. 
Table 3. Incidence of complications by VTE prophylaxis. $^{a}$

\begin{tabular}{lcrr}
\hline & $\begin{array}{c}\text { Mechanical Only } \\
(\mathbf{n}=\mathbf{2 1 1}), \mathbf{\%}(\mathbf{n})\end{array}$ & $\begin{array}{c}\text { Enoxaparin (Inpatient) } \\
(\mathbf{n}=\mathbf{1 0}), \mathbf{\%}(\mathbf{n})\end{array}$ & $\begin{array}{c}\text { Enoxaparin (2 wk) } \\
(\mathbf{n}=\mathbf{4 5}), \mathbf{\%}(\mathbf{n})\end{array}$ \\
\hline Delayed wound healing or deep infection & $0.47(1)$ & $10.0(1)$ & $8.9(4)$ \\
Hematoma & $0.95(2)$ & $0.0(0)$ & $0.0(0)$ \\
VTE & $0.47(1)$ & $0.0(0)$ & $0.0(0)$ \\
\hline
\end{tabular}

Abbreviation: VTE indicates venous thromboembolism.

${ }^{a}$ The Fisher exact test was used to compare the incidence of complications among the VTE prophylaxis methods.

direct contrast to other published protocols where the majority or entire postoperative cohort receives chemoprophylaxis. ${ }^{18,23}$ Our algorithm produced a favorable complication profile with evidence-based, selective use of LMWH. In addition to postsurgical wound and hemorrhagic complications, LMWH use is also associated with local pain, irritation, hematoma, ecchymosis, and discoloration at the injection site. $^{25}$

Multiple patient factors are known to increase VTE risk including personal history of VTE, trauma, active malignancy, and spinal cord injury and were assigned high-risk classification in our algorithm. ${ }^{1,5,26-29}$ A first-degree relative with VTE, poor mobilization postoperatively, use of prothrombotic medications, and conditions that limit pulmonary reserve including primary lung diseases, American Society of Anesthesiologists Physical Status Classification Scores greater than or equal to 3, obesity, congestive heart failure, and smoking were assigned moderate risk. ${ }^{27-29}$ Hypertension, hyperlipidemia, and diabetes mellitus have not been consistently associated with a significant increase in the risk of VTE and were assigned low risk. ${ }^{28,29}$

The type of surgery also affects the risk for VTE. It has been established that VTE risk is higher in (1) instrumentation or fusion compared with decompression alone, (2) increasing levels of fusion, (3) increasing time of procedure, and (4) combined open anteroposterior approaches. To simplify this in our algorithm, the time of procedure was analogous to the number of levels performed and

Table 4. Incidence of complications compared to reported in the literature. ${ }^{a}$

\begin{tabular}{lcc}
\hline Complication & $\begin{array}{c}\text { Study Sample } \\
(\mathbf{N}=\mathbf{2 6 6}), \% \text { (n) }\end{array}$ & $\begin{array}{c}\text { Reported in } \\
\text { Literature, \% (n) }\end{array}$ \\
\hline $\begin{array}{l}\text { Hematoma } \\
\text { Neurologic deficit from } \\
\text { bleeding complication }\end{array}$ & $0.75(2)$ & $0.3-3.5^{1,18-20}$ \\
$\begin{array}{l}\text { Delayed wound healing } \\
\text { or deep infection }\end{array}$ & $0.00(0)$ & Up to $50^{21,22}$ \\
VTE & $0.38(1)$ & $2.0-3.0^{18,20}$ \\
\hline
\end{tabular}

Abbreviation: VTE, venous thromboembolism.

${ }^{\mathrm{a}}$ The incidence of hematoma, delayed wound healing or infection, and VTE were observed at rates similar to or less than what has been previously reported in the literature. the use of a combined approach. Previously, Hohl et $\mathrm{al}^{30}$ found a $2.3 \%$ rate of symptomatic pulmonary embolism when $\geq 4$ levels were fused versus $1.4 \%$ in 3-level fusions, $0.78 \%$ in 2-level fusions, and $0.77 \%$ in 1-level fusions. Further, Dearborn et $\mathrm{al}^{31}$ and Kim et $\mathrm{al}^{32}$ found higher rates of VTE in patients who underwent major reconstructive combined anterior and posterior approaches. Therefore, $\geq 4$ levels fused and use of a combined open approach were considered high-risk surgical procedures. Posterior lumbar decompressions, anterior cervical fusions or disk replacements, and posterior cervical decompressions were considered low risk. Surgeries with risk in between the better defined low-risk and high-risk categories were assigned moderate risk and included posterior lumbar fusions at fewer than 4 levels, posterior cervical fusions, and minimally invasive spinal fusions ${ }^{1,16,26,29,31-34}$ (Table 5). Importantly, our algorithm adjusted for the risk of neurologic compromise from bleeding complications, where the risk of neurologic deterioration from compressive epidural hematoma was weighed against the risk of VTE. ${ }^{19,21,35-37}$ This allowed for a balance between the risks of bleeding and the benefits of chemical thromboprophylaxis, which is integral in spine surgery.

A recent study demonstrated similar efficacy and hemorrhagic complications compared to our study with selective use of chemoprophylaxis. The comparison by McLynn et $\mathrm{al}^{20}$ of the American College of Surgeons National Surgical Quality Improvement Program's database to institutional events found similar risk of bleeding and wound complications in the institutional cohort with selective use of chemical VTE prophylaxis $(56.3 \%$ use, mainly unfractionated heparin) as in our study $(20.7 \%$ use of LMWH). Further, no difference in the rate of VTE between mechanical and chemical prophylaxis was found when controlling for patient and procedural variables. They concluded that ubiquitous use of chemical VTE prophylaxis agents should be reconsidered in the setting of hemorrhagic complications and that risk/benefit considerations 
Table 5. Incidence of complications by thromboprophylaxis by surgery.

\begin{tabular}{|c|c|c|c|c|}
\hline Surgery & Thromboprophylaxis (\%) & $\begin{array}{c}\text { Delayed Wound } \\
\text { Healing/ } \\
\text { Deep Infection, } \\
\% \text { (n) }\end{array}$ & $\begin{array}{c}\text { Hematoma, } \\
\% \text { (n) }\end{array}$ & $\begin{array}{l}\text { VTE, } \\
\% \text { (n) }\end{array}$ \\
\hline \multirow[t]{3}{*}{ Anterior cervical fusion/disk replacement } & Mechanical only (96.4) & 0.0 & $0.9(1)$ & 0.0 \\
\hline & Enoxaparin (inpatient only) (1.8) & $50.0(1)$ & 0.0 & 0.0 \\
\hline & Enoxaparin (extended) (1.8) & 0.0 & 0.0 & 0.0 \\
\hline \multirow{3}{*}{ Anterior lumbar interbody fusion/disk replacement } & Mechanical only (50) & 0.0 & 0.0 & 0.0 \\
\hline & Enoxaparin (inpatient only) (0) & NA & NA & NA \\
\hline & Enoxaparin (extended) (50) & $33.3(1)$ & 0.0 & 0.0 \\
\hline \multirow{3}{*}{ Combined open anterior/posterior thoracolumbar fusion } & Mechanical only $(0)$ & NA & NA & NA \\
\hline & Enoxaparin (inpatient only) (0) & NA & NA & NA \\
\hline & Enoxaparin (extended) (100) & 0.0 & 0.0 & 0.0 \\
\hline \multirow[t]{3}{*}{ Extensive posterior thoracolumbar fusion ( $\geq 4$ levels) } & Mechanical only $(0)$ & NA & NA & NA \\
\hline & Enoxaparin (inpatient only) (0) & NA & NA & NA \\
\hline & Enoxaparin (extended) (100) & 0.0 & 0.0 & 0.0 \\
\hline \multirow{3}{*}{ Posterior cervical decompression } & Mechanical only (100) & 0.0 & 0.0 & 0.0 \\
\hline & Enoxaparin (inpatient only) (0) & NA & NA & NA \\
\hline & Enoxaparin (extended) $(0)$ & NA & NA & NA \\
\hline \multirow{3}{*}{ Posterior cervical fusion } & Mechanical only (90.5) & 0.0 & $5.3(1)$ & 0.0 \\
\hline & Enoxaparin (inpatient only) (9.5) & 0.0 & 0.0 & 0.0 \\
\hline & Enoxaparin (extended) $(0)$ & NA & NA & NA \\
\hline \multirow[t]{3}{*}{ Posterior lumbar decompression } & Mechanical only (89.8) & 0.0 & 0.0 & $1.9(1)$ \\
\hline & Enoxaparin (inpatient only) (0) & NA & NA & NA \\
\hline & Enoxaparin (extended) (10.1) & $33.3(2)$ & 0.0 & 0.0 \\
\hline \multirow{3}{*}{ Posterior thoracolumbar or lumbar fusion ( $\leq 3$ levels) } & Mechanical only (39.7) & $4.0(1)$ & 0.0 & 0.0 \\
\hline & Enoxaparin (inpatient only) (9.5) & 0.0 & 0.0 & 0.0 \\
\hline & Enoxaparin (extended) (50.8) & $3.1(1)$ & 0.0 & 0.0 \\
\hline
\end{tabular}

Abbreviation: VTE, venous thromboembolism; NA, not applicable.

are needed to facilitate this; however, no stratification system was offered. ${ }^{20}$ Careful and individualized consideration with a system such as the VTE Prophylaxis Risk/Benefit Score must be given to prevent both thrombotic and hemorrhagic complications.

Kepler and associates ${ }^{18}$ reviewed several studies assessing the risk of thrombosis and hemorrhage after spinal surgery and argued that the risk of postoperative thrombosis outweighed the risk of iatrogenic hemorrhage. They concluded that all spine patients should be treated with combination mechanical and chemoprophylaxis regardless of the neurologic risk of bleeding complications. ${ }^{18}$ However, the results of this present study substantiate that the risk of thrombosis as well as neurologic risk from bleeding complications can be mitigated with ubiquitous use of mechanical prophylaxis and selective use of LMWH as chemoprophylaxis.

Recommendations from both the NASS and the ACCP are important, but do not comprehensively stratify risk when recommending VTE prophylaxis. The NASS recommends reservation of chemoprophylaxis for combined anteroposterior surgery and for patients with multiple trauma, malignancy, or hypercoagulable state and recommends against chemoprophylaxis for surgeries that may be accompanied by serious wound and bleeding complica- tions. ${ }^{2}$ However, the NASS does not offer a stratification system to quantify that risk. The ACCP groups all spine surgery into 1 category without consideration of how anatomic location, the occurrence of decompression, and the occurrence of fusion influence the neurologic risk from a hemorrhagic complication. ${ }^{6,38}$

Both VTE and neurologic deterioration from epidural hematoma are rare and devastating events. While Kepler et $\mathrm{al}^{18}$ and Cox et $\mathrm{al}^{23}$ argue that the risk of postoperative thrombotic event outweighs the risk of epidural hematoma in all or most cases, we and others argue that the risk of neurologic deficit from overuse of chemoprophylaxis outweighs the risk of thrombosis on a case-by-case basis. ${ }^{14,19,20,35,37}$ These feared complications can be avoided safely and effectively with judicious use of chemical thromboprophylaxis using the VTE Prophylaxis Risk/Benefit Score.

There are limitations to our study. Although the Risk/Benefit Scores and thromboprophylaxis were assigned at the time of surgery, the development of complications was reviewed retrospectively and relied on documentation and follow-up within our healthcare system. Additionally, resumption of long-term cardioprotective aspirin was identified as a significant contributor to the development of a hemorrhagic or wound complication, but its use is 
not accounted for in our algorithm. The authors recommend that the risk of a postoperative prothrombotic state if holding aspirin be evaluated alongside the risk of wound complication in patients with known cardiovascular disease. Finally, the distribution of cervical and thoracolumbar cases may not be indicative of the distribution at other institutions depending on referral patterns and may represent varying risks of VTE and the other examined complications. The authors recognize that the implications of a cervical epidural hematoma are different than a lumbar epidural hematoma; however, the morbidity of paralysis and cauda equina syndrome is likely similar. This algorithm should be evaluated at other institutions for the purpose of external validity.

The VTE Prophylaxis Risk/Benefit Score comprehensively considers the risk of thrombotic, wound, and hemorrhagic complications and is an effective tool for determining appropriate VTE prophylaxis in degenerative spine surgery. The authors encourage other institutions to adopt this scoring system, which produces a favorable complication profile with evidence-based selective use of chemical thromboprophylaxis. The prevention of thrombotic-related complications is a priority; however, the risks of infection, delayed wound healing, and hematoma can result in permanent neurologic deficit. Evidence-based stratification of patients into low-, moderate-, and high-risk categories with corresponding VTE prophylaxis is integral to reducing both thrombotic and hemorrhagic complications.

\section{ACKNOWLEDGMENTS}

The authors would like to acknowledge Bahjat F. Qaqish, $\mathrm{PhD}$, for his contribution to statistical analysis.

\section{REFERENCES}

1. Sansone JM, del Rio AM, Anderson PA. The prevalence of and specific risk factors for venous thromboembolic disease following elective spine surgery. J Bone Joint Surg Am. 2010;92(2):304-313.

2. Bono CM, Watters WC, Heggeness $\mathrm{MH}$, et al. An evidence-based clinical guideline for the use of antithrombotic therapies in spine surgery. Spine J. 2009;9(12):1046-1051.

3. Fisher CG, Blachut PA, Salvian AJ, Meek RN, O'Brien PJ. Effectiveness of pneumatic leg compression devices for the prevention of thromboembolic disease in orthopaedic trauma patients: a prospective, randomized study of compression alone versus no prophylaxis. J Orthop Trauma. 1995;9(1):1-7.

4. Urbankova J, Quiroz R, Kucher N, Goldhaber SZ. Intermittent pneumatic compression and deep vein thrombosis prevention. A meta-analysis in postoperative patients. Thromb Haemost. 2005;94(6):1181-1185.

5. Glotzbecker MP, Bono CM, Wood KB, Harris MB. Thromboembolic disease in spinal surgery: a systematic review. Spine. 2009;34(3):291-303.

6. Gould MK, Garcia DA, Wren SM, et al. Prevention of VTE in nonorthopedic surgical patients: antithrombotic therapy and prevention of thrombosis, 9th ed: American College of Chest Physicians evidence-based clinical practice guidelines. Chest. 2012;141(2 Suppl):e227S-e277S.

7. Prevention of pulmonary embolism and deep vein thrombosis with low dose aspirin: pulmonary embolism prevention (PEP) trial. Lancet. 2000;355(9212):1295-1302.

8. Dager WE. Warfarin for venous thromboembolism prophylaxis after elective hip or knee arthroplasty: exploring the evidence, guidelines, and challenges remaining. Ann Pharmacother. 2012;46(1):79-88.

9. McGarry LJ, Stokes ME, Thompson D. Outcomes of thromboprophylaxis with enoxaparin vs. unfractionated heparin in medical inpatients. Thromb J. 2006;4:17.

10. Lassen MR, Gallus A, Raskob GE, et al. Apixaban versus enoxaparin for thromboprophylaxis after hip replacement. N Engl J Med. 2010;363(26):2487-2498.

11. Lassen MR, Raskob GE, Gallus A, Pineo G, Chen D, Portman RJ. Apixaban or enoxaparin for thromboprophylaxis after knee replacement. $N$ Engl J Med. 2009;361(6):594-604.

12. Eriksson BI, Dahl OE, Rosencher N, et al. Dabigatran etexilate versus enoxaparin for prevention of venous thromboembolism after total hip replacement: a randomised, doubleblind, non-inferiority trial. Lancet. 2007;370(9591):949-956.

13. Eriksson BI, Dahl OE, Huo MH, et al. Oral dabigatran versus enoxaparin for thromboprophylaxis after primary total hip arthroplasty (RE-NOVATE II*). A randomised, doubleblind, non-inferiority trial. Thromb Haemost. 2011;105(4):721729.

14. Eskildsen SM, Moll S, Lim MR. An algorithmic approach to venous thromboembolism prophylaxis in spine surgery. J Spinal Disord Tech. 2015;28(8):275-281.

15. Jones CE, Hollis RH, Gullick AA, et al. Venous thromboembolic events: how low can you go? Am J Surg. 2017;213(4):706-710.

16. Glotzbecker MP, Bono CM, Wood KB, Harris MB. Postoperative spinal epidural hematoma: a systematic review. Spine. 2010;35(10):E413.

17. Shiu B, Le E, Costales $\mathrm{T}$, et al. Incidence of complications after therapeutic anticoagulation in the postoperative spine trauma patient. Paper presented to Orthopaedic Trauma Association; October 9, 2015; San Diego, CA.

18. Kepler CKM, McKenzie J, Kreitz T, Vaccaro A. Venous thromboembolism prophylaxis in spine surgery. [Review]. $J$ Am Acad Orthop Surg. 2018;26(14):489-500.

19. Cheng JS, Arnold PM, Anderson PA, Fischer D, Dettori JR. Anticoagulation risk in spine surgery. Spine. 2010;35(9 Suppl):S117-124.

20. McLynn RP, Diaz-Collado PJ, Ottesen TD, et al. Risk factors and pharmacologic prophylaxis for venous thromboembolism in elective spine surgery. Spine. 2018;18(6):970-978. 
21. Gerlach R, Raabe A, Beck J, Woszczyk A, Seifert V. Postoperative nadroparin administration for prophylaxis of thromboembolic events is not associated with an increased risk of hemorrhage after spinal surgery. Eur Spine J. 2004;13(1):913.

22. Yi S, Yoon DH, Kim KN, Kim SH, Shin HC. Postoperative spinal epidural hematoma: risk factor and clinical outcome. Yonsei Med J. 2006;47(3):326-332.

23. Cox JB, Weaver KJ, Neal DW, Jacob RP, Hoh DJ. Decreased incidence of venous thromboembolism after spine surgery with early multimodal prophylaxis: clinical article. $J$ Neurosurg Spine. 2014;21(4):677-684.

24. Gerstein NS, Schulman PM, Gerstein WH, Petersen TR, Tawil I. Should more patients continue aspirin therapy perioperatively?: Clinical impact of aspirin withdrawal syndrome. Ann Surg. 2012;255(5):811.

25. Bhalla V, Abdel-Latif A, Bhalla M, Ziada K, Williams MV, Smyth SS. Meta-analysis comparing the efficacy, safety, and cost-benefit of direct acting oral anticoagulants versus enoxaparin thromboprophylaxis to prevent venous thromboembolism among hospitalized patients. Am J Cardiol. 2018;122(7):1236-1243.

26. Fineberg SJ, Oglesby M, Patel AA, Pelton MA, Singh K. The incidence and mortality of thromboembolic events in lumbar spine surgery. Spine. 2013 Jun 1;38(13):1154-9.

27. Schulte LM, O'Brien JR, Bean MC, Pierce TP, Yu WD, Meals C. Deep vein thrombosis and pulmonary embolism after spine surgery: incidence and patient risk factors. Am J Orthop. 2013;42(6):267-270.

28. Anderson FA, Spencer FA. Risk factors for venous thromboembolism. Circulation. 2003;107(23 Suppl 1):I9-16.

29. Schoenfeld AJ, Herzog JP, Dunn JC, Bader JO, Belmont PJ. Patient-based and surgical characteristics associated with the acute development of deep venous thrombosis and pulmonary embolism after spine surgery. Spine. 2013;38(21):1892-1898.

30. Hohl JB, Lee JY, Rayappa SP, et al. Prevalence of venous thromboembolic events after elective major thoracolumbar degenerative spine surgery. J Spinal Disord Tech. 2015;28(5):E310-315.

31. Dearborn JT, Hu SS, Tribus CB, Bradford DS. Thromboembolic complications after major thoracolumbar spine surgery. Spine. 1999;24(14):1471-1476.

32. Kim HJ, Kepler C, Cunningham M, Rawlins B, Boachie-
Adjei O. Pulmonary embolism in spine surgery: a comparison of combined anterior/posterior approach versus posterior approach surgery. Spine. 2011;36(2):177-179.

33. Oglesby M, Fineberg SJ, Patel AA, Pelton MA, Singh K. The incidence and mortality of thromboembolic events in cervical spine surgery. Spine. 2013;38(9):E521-527.

34. Pateder DB, Gonzales RA, Kebaish KM, et al. Pulmonary embolism after adult spinal deformity surgery. Spine. 2008;33(3):301-305.

35. Kao F-C, Tsai T-T, Chen L-H, et al. Symptomatic epidural hematoma after lumbar decompression surgery. Eur Spine J. 2015;24(2):348-357.

36. Kou J, Fischgrund J, Biddinger A, Herkowitz H. Risk factors for spinal epidural hematoma after spinal surgery. Spine. 2002;27(15):1670-1673.

37. Awad JN, Kebaish KM, Donigan J, Cohen DB, Kostuik JP. Analysis of the risk factors for the development of postoperative spinal epidural haematoma. J Bone Joint Surg Br. 2005;87(9):1248-1252.

38. Dobesh PP. Economic burden of venous thromboembolism in hospitalized patients. Pharmacother J Hum Pharmacol Drug Ther. 2009;29(8):943-953.

Disclosures and COI: There are no conflicts of interest. Biostatistical analysis was grant funded by UNC-Chapel Hill's NC TraCS Institute CTSA-UL1TR002489. Institutional Review Board approval was obtained prior to the initiation of this study.

Corresponding Author: Joshua A. Shapiro, MD, 130 Mason Farm Rd \#3155, Chapel Hill, NC 27599. Phone: (919) 966-9166; Fax: (919) 966-6730; Email: joshua.shapiro@unchealth.unc.edu.

Published 28 August 2020

This manuscript is generously published free of charge by ISASS, the International Society for the Advancement of Spine Surgery. Copyright (c) 2020 ISASS. To see more or order reprints or permissions, see http://ijssurgery.com. 